\title{
Assessing the sustainability of harvest of the European Turtle-dove along the European western flyway
}

\author{
HERVÉ LORMÉE ${ }^{1 *}$ (D), CHRISTOPHE BARBRAUD ${ }^{2}$, WILL PEACH ${ }^{3}$, \\ CARLES CARBONERAS ${ }^{3}$, JEAN DOMINIQUE LEBRETON ${ }^{4}$, \\ LARA MORENO-ZARATE ${ }^{5}$, LEO BACON ${ }^{6}$ and CYRIL ERAUD ${ }^{1}$
}

${ }^{1}$ Office National de la Chasse et de la Faune Sauvage, 79360 Villiers en Bois, France.

${ }^{2}$ Centre d'Etudes Biologiques de Chizé, UMR 7372, CNRS - Université La Rochelle, 79360 Villiers-en-Bois, France.

${ }^{3} R S P B$ Centre for Conservation Science, RSPB, The Lodge, Sandy, Bedfordshire SG19 2DL, UK.

${ }^{4}$ Centre d'Ecologie Fonctionnelle \& Evolutive, CNRS, 34293 Montpellier, France.

${ }^{5}$ Instituto de Investigación en Recursos Cinegéticos (IREC) (CSIC-UCLM-JCCM), Ronda de Toledo, 12, 13005 Ciudad Real, Spain.

${ }^{6}$ Office National de la Chasse et de la Faune Sauvage, Unité Avifaune Migratrice, La Tour du Valat, Le Sambuc, FR-13200 Arles, France.

*Author for correspondence; email: herve.lormee@oncfs.gouv.fr

(Received o9 July 2019; revision accepted o2 November 2019)

\section{Summary}

With a decline exceeding 30\% over three generations, the once-common European Turtle-dove is now considered globally threatened by IUCN. As a legal game species in to European countries, the recent International Single Species Action Plan for this species highlighted the need to carry out an assessment of the sustainability of current levels of hunting. In 2013-2014, the Western European population was estimated at 1.3-2.1 million pairs, and the hunting bag in the same region to be 1.1 million birds. Using the Demographic Invariant Method, we assessed whether current levels of hunting harvest within Europe constitute overexploitation of the western flyway European Turtledove population. We calculated the maximum growth rate $\lambda_{\max }$ that a population might achieve in the absence of any additive mortality. Then we estimated the potential maximum harvestable population fraction $(\mathrm{P})$ allowed by excess population growth. We explored a wide range of plausible scenarios relating to assumed demographic rates, geographic scope of the flyway and management objectives. $\lambda_{\max }$ was estimated to lie between 1.551 and 1.869 . Current levels of hunting along the western flyway are more than double the sustainable fraction $(\mathrm{P})$ under all suitably conservative scenarios, and only fall below this threshold under the most restrictive assumptions. We conclude that current levels of legal hunting along the western flyway are unlikely to be sustainable. Reducing uncertainty associated with assessments of the sustainability of turtle dove hunting will require improved information on (in order of decreasing importance) current levels of hunting, adult survival, age structure and population size.

Keywords: harvest sustainability, turtle dove, Demographic Invariant Method, migrant bird, legal hunt. 


\section{Introduction}

The management of animal populations exploited by man requires assessment if populations are able to sustain that source of mortality (Lebreton 2005). The capacity of an animal population to sustain exploitation can be estimated by comparing the proportion of individuals killed by this additional source of mortality against potential population growth (Robinson and Redford 1991, Wade 1998).

The European Turtle-dove Streptopelia turtur (hereafter 'turtle dove') is a long-distance migratory species breeding across a large area of the Western Palearctic, from the Iberian Peninsula to Russia, and wintering in sub-Saharan Africa (Jarry 1995). The overall European population is estimated at 3.2 to 5.9 million pairs (BirdLife International 2015). Generation length (the average age of parents of the current cohort) is given as 5.3 years (BirdLife International 2017) and on average two to four clutches of two eggs are laid between May and August (Fisher et al. 2018). The species can be legally hunted in 1o European countries (European Union 2009) and has undergone a large, generalised population decline across its European range of $33 \%$ since 1998, and $29 \%$ between 2007 and 2016 (PECBMS 2019: https://pecbms.info/trends-and-indicators/speciestrends/), leading IUCN to change its status in 2015 from 'Near Threatened' to 'Vulnerable' (BirdLife International 2017).

Several mechanisms may have contributed to this population decline. Studies in the UK suggest that a reduction in breeding productivity linked to agricultural intensification has played a key role (Browne and Aebischer 2004, Browne et al. 2005, Dunn et al. 2017). Wintering conditions in Africa could also have contributed to population decline through increased mortality due to drought, and consecutive reductions in food supply or eventually through hunting targeting congregations of roosting birds (Eraud et al. 2009, Zwarts et al. 2009). In the context of this decline, as several hundred thousand turtle doves are legally shot each year, particularly in southern Europe (Boutin and Lutz 2007, Fisher et al. 2018), the sustainability of the harvest needs to be considered. The guidance document on hunting under the EU Birds Directive states "so that hunting does not lead to the decline of huntable species, the general approach in wildlife management is to ensure that the hunting of species does not exceed the range between "maximum" and 'optimum" sustainable yield" (European Union 2009). The recent International Single Species Action Plan for the turtle dove (Fisher et al. 2018) emphasises the lack of knowledge concerning the potential impact of hunting on population trends, and the need for an assessment of the sustainability of the current levels of hunting to inform the long-term conservation of the species at local and international levels.

The aim of this study is therefore to evaluate whether current levels of legal harvest of turtle dove populations in Western Europe are sustainable or not. We focus on the Western European countries because this region accounts for the largest share of the harvest within Europe $(>60 \%$; Fisher et al. 2018), and also provides much more comprehensive information on hunting bags, population sizes and demography. Recent studies indicate a migratory divide between western and central migratory flyways (Marx et al. 2016), so this evaluation can be conducted independently of Central and Eastern Europe.

Ideally, estimates of population growth rate needed to estimate harvest sustainability should be derived from population models parameterised with estimates of demographic parameters (e.g. age or stage specific survival, productivity and age at first breeding). However, for many exploited animal populations, some of these demographic parameters are unknown or poorly estimated (Lebreton 2005, Elmberg et al. 2006) particularly juvenile survival, age at first breeding or productivity. In order to detect overharvested bird populations from incomplete data, Niel and Lebreton (2005) developed a Demographic Invariant Method (DIM) based on the empirical constancy across bird species of the maximum population growth rate per generation. The DIM has the advantage of requiring limited demographic information, specifically estimates of adult survival and age at first breeding. This approach is relevant for the turtle dove as detailed age-specific 
information required to develop a full demographic model are lacking, while estimates of adult survival are available for the western flyway population.

Here we apply the DIM approach to the western flyway turtle dove population in order to assess whether current levels of hunting harvest are likely to overexploit these populations. As age at first breeding is not accurately known for turtle doves, we derive this from other migratory species. As far as we know this is the first quantitative assessment of the sustainability of the widespread legal hunting of this globally 'Vulnerable' species. We account for uncertainty and partial knowledge of species traits by considering a wide range of plausible scenarios based on a range of demographic rates, geographic definitions of the flyway population and management objectives, and by developing a sensitivity analysis to identify the parameters critical for inferences on the risk of overharvest that need to be estimated with greater precision in the future.

\section{Methods}

\section{Study area - delimitation of the western flyway}

The term flyway refers to the entire annual range of a migratory bird species, from breeding to wintering grounds, including stopover sites and areas overflown by birds while migrating (Boere and Stroud 2006). We define the western flyway population of turtle dove following Marx et al. (2016). This study showed that most turtle doves (more than $90 \%$ of ring recoveries) breeding in France, Ireland, Portugal, Spain, Switzerland, Germany and United Kingdom migrated through France, Spain and Portugal during postnuptial migration. The Spanish ringing dataset contains additional recovery data of birds originating from Belgium and the Netherlands (SEO/BirdLife 2012), so we considered both those countries to be part of the western flyway and included their breeding populations in our calculations. Marx et al. (2016) considered that turtle doves breeding in Italy were associated with the central European flyway. However, a substantial number of turtle doves ringed in France and eastern Spain during spring migration have been recovered (both during spring and autumn migration) in northern Italy, and birds ringed in northern Italy (during spring migration) have been recovered during autumn in south-western Europe (Spina and Volponi 2008, Escandell 2011). These data suggest a proportion of the northern Italian breeding population migrates along the western flyway. To reflect the uncertainty of the flyway status of turtle doves breeding in northern Italy, we conducted our hunting sustainability calculations including and excluding the northern Italian contributions to flyway population size and hunting statistics. Northern Italy is defined as the area lying north of a line from La Spezia $\left(44^{\circ} 6^{\prime} 14^{\prime \prime} \mathrm{N}, 9^{\circ}\right.$ $49^{\prime} 35^{\prime \prime}$ E) to Comacchio ( $44^{\circ} 41^{\prime} 43^{\prime \prime} \mathrm{N}, 12^{\circ} 10^{\prime} 38^{\prime \prime}$; Figure 1 ).

\section{Hunting bag statistics}

For all countries except Spain, recent estimates of annual numbers of birds legally hunted were taken from Fisher et al. (2018) and relate to the August 2013 to February 2014 hunting season (Table 1). For Spain, we used a more recent and updated estimation for the same season derived through direct consultation with regional hunting authorities and corrected for under-reporting (Arroyo et al. 2018).

To extrapolate the proportion of the Italian hunting bag associated with the western flyway, we based our approach on the Italian bird migration atlas (Spina and Volponi 2008). Among the 102 birds both ringed and recovered in Italy, nineteen (18.6\%) were reported in the northern third of the country (as defined for population size), most often through hunting (more than $90 \%$ of recoveries). Applying this proportion to the Italian hunting bag provided an estimate of hunting in this northern area. The mean annual hunting bag for turtle doves in Italy was 305,590 during 2004-2014 (Sorrenti and Tramontana 2016), leading to an estimate of 56,840 birds in the northern part of Italy. 


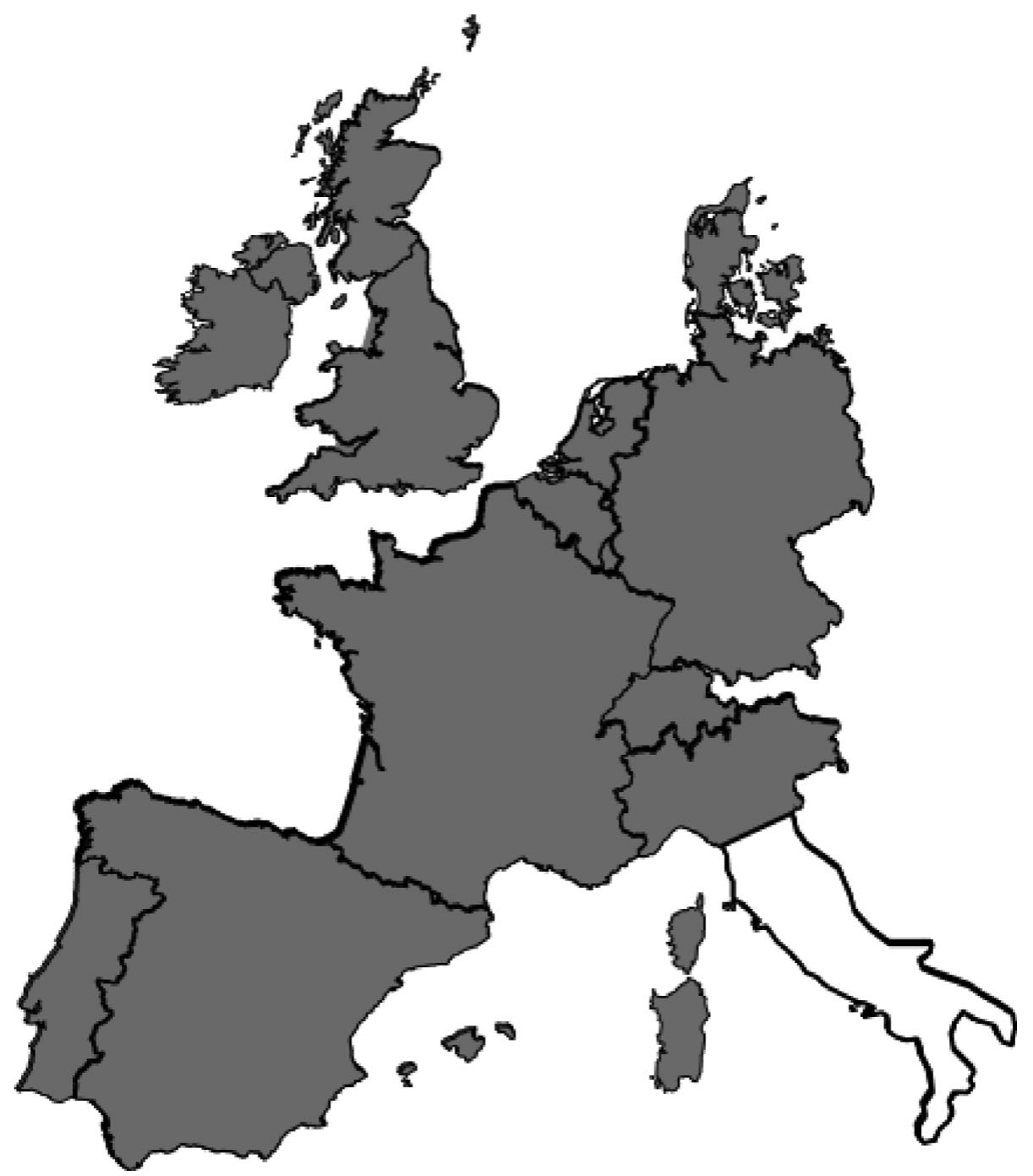

Figure 1. Map showing European countries included in the western flyway (in grey). Only the northern third of Italy was taken into account.

\section{Estimating the maximal population growth rate $\left(\lambda_{\max }\right)$}

The maximum growth rate that a turtle dove population might achieve in the absence of any additive mortality $\left(\lambda_{\max }\right)$ was estimated by solving numerically the equation proposed by Niel and Lebreton (2005) for short-lived species:

$$
\lambda_{\max }=\exp \left(\left[\mathrm{a}+\mathrm{So} /\left(\lambda_{\max }-\mathrm{So}\right)\right]^{-1}\right)
$$

Where ' $\mathrm{a}$ ' is the average age at first reproduction and 'So' the adult survival rate under optimal growth conditions. Turtle doves are able to breed in their second calendar year (Cramp 1985) but it is unlikely that all individuals breed at this age. The average age of first breeding is known for rather few bird species and, as an indirect estimate of this parameter, we applied the known 
Table 1. Number of turtle doves harvested (legal hunting) in European countries located under the western flyway. In all countries but Italy, hunting bags were obtained during the 2013-2014 hunting season. Data for France, Portugal and Italy are from Fisher et al. (2018). Spanish hunting bag is from Arroyo et al. (2018).

\begin{tabular}{llr}
\hline Country & Hunting season & Hunting bag \\
\hline France & $2013-2014$ & 91,704 \\
Portugal & $2013-2014$ & 109,815 \\
Spain & $2013-2014$ & 885,554 \\
Northern Italy* & $2004-2014$ (annual average) & 56,840 \\
Total (northern Italy included) & & $1,143,913$ \\
Total (Italy excluded) & & $1,087,073$ \\
\hline
\end{tabular}

* We considered that only $18 \%$ of the Italian hunting bag $(n=305,590$ hunted birds) contained birds related to the Western European flyway (see methods section), which leads to a hunting bag of 56,840 birds.

distribution for another multi-brooded, sub-Saharan migratory and short-lived species the barn swallow Hirundo rustica (Jarry 1980). In this species, 90\% of individuals breed for the first time in their second calendar year (aged one year) and 10\% in their third calendar year (aged two years), corresponding to a mean age at first breeding of 1.1 years. While this estimate is indirect, it is probably conservative with respect to the estimation of a maximum growth rate (i.e. likely to be biased high), as one might predict that in a relatively large bird such as the turtle dove, that now occurs at low density in many parts of the breeding range (Dunn and Morris 2012), potentially hindering pair formation, the proportion of birds breeding for the first time at age two and above could well be higher.

Accurate estimates of true adult survival are difficult to obtain as estimates are often based on live capture-recapture data in which mortality and emigration are confounded (Lebreton et al. 1992, Dillingham and Fletcher 2008, Johnson et al. 2012). Furthermore, these estimates are generally not obtained under optimal conditions (i.e. in the absence of any additive mortality which might include hunting losses in the case of game species). To minimise these problems, and in order to cover the potential range of this parameter in this species, our analyses use two different survival estimates: one empirical and one derived from a well-established body size relationship. The lower empirical estimate (0.623) is derived from British ring recoveries (with therefore no underestimation bias due to permanent emigration) during a period of population stability implying that any additive mortality may have been minimal (Siriwardena et al. 2000). A higher derived estimate comes from an empirical multi-species relationship between survival and body mass for captive individuals held in zoos (Ricklefs 200o). The latter provides an upper plausible limit for adult survival and could be considered as the intrinsic biological maxima since individuals in zoos were probably not exposed to natural sources of mortality. Our estimate of So (adult survival) was derived from the equation provided by Johnson et al. (2012) based upon data in Ricklefs (2000) as:

$$
\text { So }=\mathrm{p}^{1 /(\exp [3.22+0.24 * \log (\mathrm{M})+\mathrm{e}]-1)}
$$

where $\mathrm{p} \sim$ beta $(3.34,101.24)$, e $\sim \operatorname{Normal}\left(0, \sigma_{2}=0.087\right)$, and $\mathrm{M}$ is body mass (in kg). A mean adult body mass of $153 \mathrm{~g}$ ( \pm 0.16 SE) was calculated from a sample of 6,083 adult turtle doves captured in France (unpublished data from the Office National de la Chasse et de la Faune Sauvage "Colombides" ringing scheme). Following this approach we obtained a higher value for So of o.839.

\section{Estimating sustainability indices}

The potential maximum harvestable population fraction (P) allowed by excess growth was estimated following Wade (1998) as:

$$
\mathrm{P}=\mathrm{N} \times \mathrm{f} \times\left(\lambda_{\max }-1\right)
$$


where $\mathrm{N}$ is the total population size before harvest occurs, $\mathrm{f}$ is a management uncertainty factor ranging from 0.1 to 1 , allowing for a range of unknown entities such as density dependence affecting demographic rates, any additional unknown sources of additive mortality as well as any management objectives or conservation concerns (Williams et al. 2002, Johnson et al. 2012).

As most hunting bags were obtained for the 2013-2014 hunting season, we estimated the size of the western flyway turtle dove population $(\mathrm{N})$ in 2013 , before the harvest occurred. Our estimate of population size included all mature individuals at the onset of the breeding season and juveniles produced in 2013, i.e. the population at the end of the breeding period.

For each country within the western flyway in which turtle doves breed, we used the most recent available population estimates (from Fisher et al. 2018). These estimates rely upon counts of singing males during the breeding season, which are then converted into the number of breeding adults by doubling the number of singing males. Each country-specific population size estimate was associated with lower and upper bounds. In some cases these were statistical confidence limits (UK, France), in others they reflected the number of "certain" and "possible plus certain" counts of breeding pairs (Denmark, Germany), and in others were the limits defined on the basis of expert opinion (Belgium, Portugal, Switzerland, Italy). No data were available to estimate the proportion of the Italian turtle dove breeding population located in the northern third of Italy. We therefore calculated the percentage of the national territory located in the northern part of Italy and then extrapolated this percentage to the national breeding population size estimate. We excluded the alpine chain area from this calculation as turtle doves only breed below $600-800 \mathrm{~m}$ in northern Italy (Spina and Volponi 2008). The area of interest covered $21 \%$ of the entire area of Italy; our estimate assumed an even density distribution of turtle doves across Italy.

For each country we extrapolated the upper and lower population estimates for the most recent census year to a common reference year of 2013 using country-specific estimates of inter-annual changes in abundance obtained from the Pan-European Common Bird Monitoring Scheme (hereafter PECBMS). Breeding population size in 2013 (Table 2) was calculated as the product of the census and the ratio between the abundance indices in 2013 and the census year. Although we calculate P for both the upper and lower population estimates, several authors stress the need to adopt a conservative minimum population estimate when assessing the sustainability of harvest losses (Wade 1998, Niel and Lebreton 2005, Dillingham and Fletcher 2008).

In order to estimate total population size in 2013, including breeding adults and juveniles produced in that year, we developed a simple two age-class Leslie matrix model to estimate the stable age distribution q (details in Appendix $\mathrm{S}_{1}$ in the online supplementary material). In contrast to the DIM approach which relies on demographic parameters on the absence of additive mortality, the objective of the Leslie matrix modelling is to estimate the age structure (ratio of adults to juveniles) associated with a stable population. Different demographic parameters were therefore used for the Leslie matrix modelling, which reflect the current demographic status of the population. The Leslie matrix model indicated the stable age structure of the turtle dove population to be $55.92 \%$ juveniles and $44.08 \%$ adults (Appendix SI).

The management uncertainty factor ' $\mathrm{f}$ ' allows for several potential sources of uncertainty including unknown additive sources of mortality and positive density dependence (e.g. reduced mating efficiency at low population densities) (Wade 1998, Niel and Lebreton 2005). It also allows for a more cautious approach to be adopted for declining or vulnerable populations. Dillingham and Fletcher (2008) suggest that the adopted value of $f$ should reflect the conservation status of the species in question and recommend a value of 0.5 for 'Least Concern' species, 0.3 for 'Near Threatened', and o.I for globally threatened species. The turtle dove is globally threatened, in rapid and continuing decline across Europe and is hunted to an unknown extent in north and subSaharan Africa (Zwarts et al. 2009).

We therefore calculate $P$ using three definitions of $f$ : the more conservative value 0.1 as recommended for globally threatened species, an intermediate value of 0.2 and a less conservative value of 0.3 recommended for Near Threatened species. We calculated P including and excluding the hunting and breeding population data for northern Italy, as explained above, for the high and 
Table 2. Estimated turtle dove breeding population sizes in 2013 for countries located in the Western European flyway. For Italy, the area under concern covered $21 \%$ of national territory (northern part); we therefore applied this ratio to the national population size used in our approach $(33,335-66,670)$. All population sizes are indicated as $10^{3}$ breeding pairs.

\begin{tabular}{|c|c|c|c|c|c|c|c|c|c|}
\hline \multirow[t]{2}{*}{ Country } & \multicolumn{2}{|c|}{ Population size } & \multirow[t]{2}{*}{ Year(s) of estimate } & \multirow[t]{2}{*}{ Year of reference (I) } & \multirow[t]{2}{*}{$\begin{array}{l}\text { Abundance index } \\
\text { in the reference year }\end{array}$} & \multirow[t]{2}{*}{$\begin{array}{l}\text { Abundance } \\
\text { index in } 2013\end{array}$} & \multirow[t]{2}{*}{$\begin{array}{l}\text { Ratio between } \\
\text { abundance indexes }\end{array}$} & \multicolumn{2}{|c|}{$\begin{array}{l}2013 \text { Population } \\
\text { size (2) }\end{array}$} \\
\hline & Min & Max & & & & & & Min & Max \\
\hline Belgium & 3 & 4.5 & $2000-2002$ & 2001 & 35 & 10 & 0.28 & 0.857 & 1.286 \\
\hline Denmark & 0.100 & 0.150 & $2010-2011$ & 2011 & $-*$ & $-*$ & 1 & 0.1 & 0.15 \\
\hline France & 396.985 & 481.007 & 2009 & 2009 & 75 & 57 & 0.76 & 301.709 & 365.565 \\
\hline Germany & 25 & 45 & $2005-2009$ & 2007 & 73 & 45 & 0.62 & 15.411 & $27 \cdot 740$ \\
\hline Italy & 150 & 300 & 2006 & 2006 & 103 & 109 & 1.06 & 158.738 & $317 \cdot 476$ \\
\hline Netherlands & 1.200 & 1.400 & $2013-2015$ & 2014 & 13 & 13 & 1 & 1.200 & 1.400 \\
\hline Portugal & 10 & 50 & $2008-2012$ & 2010 & 59 & 30 & 0.51 & 5.085 & 25.424 \\
\hline Spain & 1370 & 2285 & $2004-2006$ & 2005 & 100 & 70 & 0.70 & 959 & I 599.500 \\
\hline Switzerland & 1 & 2.500 & $1993-1996$ & 1995 & $100^{* *}$ & 45 & 0.45 & 0.475 & 1.125 \\
\hline UK & 3.220 & $5 \cdot 460$ & 2014 & 2014 & 3 & 4 & 1.33 & 4.293 & 7.280 \\
\hline
\end{tabular}

(1)Median year within the period over which the population size was estimated; (2) 2013 population size calculated as: initial population size $\times$ ratio [abundance index in 2013 / abundance index in reference year of last population census].

* abundance indexes not known; population size considered as in the last census (2011).

** monitoring of abundance started in 1999, therefore last census was used as if collected in 1999 . 
low population size estimates and for the high and low So estimates. For each P calculation scenario, we evaluated whether current levels of hunting exceed the theoretical maximum sustainable harvest level, by calculating the sustainability index:

$$
S I=P / n
$$

Where $\mathrm{n}$ is the number of turtle doves currently hunted. If $S I<1$ then current hunting levels are likely to be unsustainable (Niel and Lebreton 2005).

\section{Sensitivity of sustainability indices and influential parameters}

We conducted a sensitivity analysis to identify the individual demographic parameters whose uncertainty most influenced the sustainability indices (adult survival, age at first breeding, population size, age distribution and hunting bag), and therefore our inferences about the risk of overharvest. The aim of this analysis was to identify the parameters for which more information is needed to enhance the robustness of any inferences relating to potential overharvest of the species. The uncertainty of each demographic parameter (So, a, n, q, N) was modelled using a probability distribution corresponding to our best current knowledge. Uncertainty distributions for each parameter were obtained using $1,000,000$ iterations where independent values for each parameter were drawn randomly from their respective distributions. The proportional contribution of the variance of each entry parameter $\theta(S, a, n, q, N)$ to the variance of the estimated parameters $E$ $\left(\lambda_{\max }, \mathrm{P}, \mathrm{SI}\right)$ were estimated using the delta method (Seber 1982). We used the value of P obtained in the intermediate scenario $(f=0.2)$, and $\mathrm{N}$ value corresponding to the total population size (adults only) including northern Italy. Further details are provided in Appendix S2.

\section{Results}

\section{Hunting bag, population size and maximal population growth}

For the hunting season 2013-2014, we estimate the total (legal) turtle dove hunting bag for the entire European western flyway to be $1,143,913$ including northern Italy and 1,087,073 excluding northern Italy (Table 1 ).

The western flyway breeding population in 2013 was estimated to be $1,321,465-2,096,140$ breeding pairs $(2,642,930-4,192,280$ adults) including northern Italy, and 1,288, 130-2,029,470 $(2,576,260-4,058,940$ adults) excluding Italy (Table 2$)$. Adding $55.92 \%$ juveniles lead to a total population size of 5,995,758-9,510,617 individuals including northern Italy, and 5,844,510$9,208,122$ individuals excluding Italy. The maximum population growth rate $\left(\lambda_{\max }\right)$ was estimated to lie between 1.551 (So $=0.836)$ and $1.869($ So $=0.623)$.

\section{Sustainability of hunting}

The observed level of legal hunting across the European western flyway exceeded the theoretical maximal harvestable fraction $(\mathrm{P})$ that the population can sustain in $67 \%$ of scenarios $(0.30<\mathrm{SI}<$ 0.93; Table 3). Under the most conservative management scenario $(f=0.1)$ as recommended for vulnerable species, the observed level of legal hunting across the European western flyway always far exceeded $\mathrm{P}$, irrespective of maximum population growth rate and geographic scope (inclusion/ exclusion of northern Italy), the equivalent excess being 286,887-813,547 hunted doves. Current levels of legal hunting were only comfortably less than the maximum harvestable fraction (SI > 1.I) when we assumed maximum population size and growth and adopted the least stringent management objective $(f=0.1: 0 \%, f=0.2: 25 \%$ of scenarios, $f=0.3: 75 \%$ of scenarios; table 3 ). Thus, the current level of legal hunting along the western flyway far exceeds the potential levels of 
Table 3. Maximum harvestable population fraction $(\mathrm{P})$ and sustainability index (SI) obtained using $\mathrm{f}$ values of $0.1,0.2$, 0.3. Each geographic group (with or without northern Italy) includes 4 trials in which $\mathrm{P}$ is calculated both for lower and upper estimation of population size and for low ( $\left.\mathrm{P}_{1}\right)$ and high $\left(\mathrm{P}_{2}\right)$ values of $\lambda_{\max }$.

\begin{tabular}{|c|c|c|c|c|}
\hline & \multicolumn{2}{|c|}{ Northern Italy excluded } & \multicolumn{2}{|c|}{ Northern Italy included } \\
\hline & Min & Max & Min & Max \\
\hline Population size (number of individuals) & $5,844,510$ & $9,208,122$ & $5,995,758$ & $9,510,617$ \\
\hline European hunting bag in western flyway & \multicolumn{2}{|c|}{$1,087,073$} & \multicolumn{2}{|c|}{$1,143,913$} \\
\hline $\mathrm{f}=\mathrm{O} . \mathrm{I}$ & \multicolumn{4}{|c|}{ Maximum harvestable population fraction $(\mathrm{P})$} \\
\hline$P_{1}\left(\right.$ for $\left.\lambda_{\max }=1.551\right)$ & 322,033 & 507,368 & 330,366 & 524,035 \\
\hline $\mathrm{P}_{2}\left(\right.$ for $\left.\lambda_{\max }=1.869\right)$ & 507,888 & 800,186 & 521,031 & 826,473 \\
\hline SI for $\mathrm{P}_{1}$ & 0.30 & 0.47 & 0.29 & 0.46 \\
\hline SI for $\mathrm{P}_{2}$ & 0.47 & 0.74 & 0.46 & 0.72 \\
\hline$f=0.2$ & \multicolumn{4}{|c|}{ Maximum harvestable population fraction $(\mathrm{P})$} \\
\hline$P_{1}\left(\right.$ for $\left.\lambda_{\max }=1.551\right)$ & 644,065 & $1,014,735$ & 660,733 & $1,048,070$ \\
\hline $\mathrm{P}_{2}\left(\right.$ for $\left.\lambda_{\max }=1.869\right)$ & $1,015,776$ & $1,600,372$ & $1,042,063$ & $1,652,945$ \\
\hline SI for $P_{1}$ & 0.59 & 0.93 & 0.58 & 0.92 \\
\hline SI for $\mathrm{P}_{2}$ & 0.93 & 1.47 & 0.91 & 1.44 \\
\hline $\mathrm{f}=0.3$ & \multicolumn{4}{|c|}{ Maximum harvestable population fraction $(\mathrm{P})$} \\
\hline$P_{1}\left(\right.$ for $\left.\lambda_{\max }=1.551\right)$ & 966,098 & $1,522,103$ & 991,099 & 1,572105 \\
\hline $\mathrm{P}_{2}\left(\right.$ for $\left.\lambda_{\max }=1.869\right)$ & $1,523,664$ & $2,400,557$ & $1,563,094$ & $2,479,418$ \\
\hline SI for $\mathrm{P}_{1}$ & 0.89 & 1.40 & 0.87 & 1.37 \\
\hline SI for $\mathrm{P}_{2}$ & 1.40 & 2.21 & 1.37 & 2.17 \\
\hline
\end{tabular}

excess growth predicted for this population under the large majority of scenarios, suggesting that the current hunting take is likely to be unsustainable.

\section{Sensitivities}

Irrespective of the value used for adult survival, mean SI was substantially lower than I (Table 4). Based on the simulated parameter estimates and for $\mathrm{So}=0.836$ and 0.623 , the respective probability that SI was lower than I was 0.964 and 0.852 .

Uncertainty in the parameter $\lambda_{\max }$ was more sensitive to uncertainty in adult survival than to uncertainty in the age at first breeding (Table 5). Uncertainty in the potential maximum harvestable population fraction $(\mathrm{P})$ was most sensitive to uncertainty in adult survival, age distribution and population size but relatively insensitive to uncertainty in the age at first breeding. Uncertainty in the sustainability index was highly sensitive to uncertainty in the size of the hunting bag but relatively insensitive to uncertainty in other demographic parameters (Table 5).

\section{Discussion}

\section{Evidence for overharvesting}

Previous turtle dove management plans have noted that high hunting pressure might be a potential source of unsustainable mortality (Boutin 2001, Boutin and Lutz 2007). However, no previous attempt has been made to investigate the sustainability of current hunting levels, a necessary step to secure a consensus between stakeholders about the impact of hunting on turtle dove populations and ultimately to implement sustainable management of this species. 
Table 4. Mean and SD estimates of sustainability parameters from the sensitivity analysis. Results are shown for the two survival estimates. With $\lambda_{\max }$ : maximum population growth rate, P: potential maximum harvestable population fraction (with $\mathrm{f}=0.2$ ), SI: sustainability index.

\begin{tabular}{llllll}
\hline & $\begin{array}{l}\text { Low survival } \\
(\text { So }=0.623)\end{array}$ & & & $\begin{array}{l}\text { High survival } \\
(\text { So }=0.836)\end{array}$ & \\
\cline { 2 - 3 } & Mean & SD & Mean & SD \\
\hline$\lambda_{\max }$ & 1.857 & 0.204 & & 1.492 & 0.274 \\
$\mathrm{P}$ & 1360702 & 371886 & & 780473 & 450667 \\
$\mathrm{SI}$ & 0.704 & 0.283 & & 0.404 & 0.269 \\
\hline
\end{tabular}

Table 5. Sensitivities of the sustainability parameters $\left(\lambda_{\max }, \mathrm{P}\right.$ and SI) to uncertainty in the values of adult survival, age at first breeding, population size, age distribution and hunting bag. Table entries show the proportional contribution of the variance of each entry parameter ( $\mathrm{So}, \mathrm{a}, \mathrm{N}, \mathrm{q}, \mathrm{n}$ ) to the variance of the derived parameters $\left(\lambda_{\max }, \mathrm{P}, \mathrm{SI}\right)$. $\lambda_{\max }$ : maximum population growth rate, P: potential maximum harvestable population fraction, SI: sustainability index, So: adult survival.

\begin{tabular}{llll}
\hline & $\lambda_{\max }$ & $\mathrm{P}$ & $\mathrm{SI}$ \\
\hline So $=0.623$ & & & \\
Survival (So) & 0.565 & 0.365 & 0.064 \\
Age at first breeding (a) & 0.435 & 0.038 & 0.006 \\
Population size (N) & & 0.268 & 0.044 \\
Age distribution (q) & & 0.328 & 0.053 \\
Hunting bag (n) & & & 0.833 \\
So $=.836$ & 0.612 & & \\
Survival (So) & 0.388 & 0.580 & 0.105 \\
Age at first breeding (a) & & 0.007 & 0.001 \\
Population size (N) & & 0.131 & 0.024 \\
Age distribution (q) & 0.282 & 0.052 \\
Hunting bag (n) & & & 0.817 \\
\hline
\end{tabular}

Our findings clearly indicate that current levels of hunting along the western flyway of the European Turtle-dove population exceed, probably by a considerable margin, the maximum harvestable fraction predicted by the life history of the species. This conclusion is robust to a wide range of assumptions about demographic rates, geographic scope of the flyway and the extent to which management objectives should be cautious for a globally threatened rapidly declining species (Table 3). Under the most conservative scenario $(f=0.1)$, the number of individuals harvested was 1.35-3.37 times P when excluding Italy (1.4-3.6 times including Italy). Even under the least conservative scenario ( $f=0.3$ ), assuming maximum population size and growth, there were still two out of eight cases where the harvest exceeded P. This conclusion is robust to the levels of uncertainty associated with the demographic parameters we used, with a very high probability that SI was lower than 1.

In our approach, we followed the recommendations of previous workers (Wade 1998, Niel and Lebreton 2005, Dillingham and Fletcher 2008, Johnson et al. 2012), who stressed the need to adopt conservative values of $\mathrm{f}$ and lower estimates of population size (see also Taylor et al. 2000 and Runge et al. 2009). We also wanted to explore some less conservative scenarios to inform future discussions with a range of stakeholders, including hunting organisations. We stress our estimate of current hunting levels for turtle doves should be considered as a minimum value as it does not allow for crippling losses associated with shooting (deaths caused by wounds or lead poisoning; Schulz et al. 2006), the failure of statutory reporting agencies to correct for incomplete bag returns 
in official national hunting statistics (Arroyo pers. comm.) or any illegal hunting in Europe (Brochet et al. 2016 estimated that 600,000 turtle doves might be illegally killed each year in the Mediterranean region) or legal hunting outside the EU. Zwarts et al. (2009), for example, report intense shooting at roosts and drinking pools in Mali and Senegal. Mortality associated with crippling losses is also likely to be demographically important: in another hunted dove species (Mourning Dove Zenaida macroura), estimates of crippling rate ranged from 10 to $41 \%$ across studies (Schulz et al. 2006). These unreported sources of hunting mortality strengthen the case for placing more emphasis on our more conservative scenarios $(f=0.1)$ in discussions of future harvest levels.

\section{Improving availability, accuracy and precision of demographic parameters}

Our sensitivity analyses highlight the need to measure three parameters with greater precision in order to increase the robustness of the estimates of the potential maximum harvestable population fraction and the sustainability index. These are in order of decreasing importance: the number of turtle doves harvested, the adult survival rate, the age distribution and population size. Official national hunting statistics are published only every few years in some countries and harvest statistics are often associated with a high degree of uncertainty mainly as a consequence of low return rates from hunters (Aubry et al. 2016). A recent study in Spain has found that official Government statistics generally do not correct for the failure of some hunting estates (or even provinces) to submit hunting returns in every year (Arroyo et al. 2018). Much greater effort is needed from Government agencies to ensure that the official national hunting statistics are accurate and complete, and reported in a timely fashion.

The design of future hunting reporting schemes should consider new approaches to maximise annual reporting by hunters. One option to increase the accuracy and completeness of hunting bag returns would be the introduction of personal harvest notebooks that individual hunters would be required to return to hunting federations at the end of each hunting season. The submission of this notebook would be mandatory, within a defined time limit, otherwise the hunter would forfeit a permit to hunt in the following year. Moreover, smartphone applications have been introduced that allow the collection of hunting data in real time. This could speed up the data collection process and potentially improve the efficiency of the management of any national bag limit. Such a system is currently being tested in Malta with promising results (Wild Birds Regulation Unit pers. comm.). Harvest data should be submitted, collated and published on a yearly basis in order to evaluate how harvest levels are changing over time. Publication of the annual harvest data by the following spring would potentially give regulatory authorities sufficient time to set bag limits for the following hunting season based on a knowledge of changes in breeding population (from national bird population monitoring schemes) and the size of the hunting bag from the previous calendar year.

In addition to improved reporting of the hunting bag, we recommend implementing studies designed to assess crippling losses associated with turtle dove hunting, as research on Mourning Dove indicate this source of mortality to be substantial (Schulz et al. 2006).

One of the main restrictions we faced in applying the DIM, and which would severely restrict any future application of matrix models, is the general absence of demographic information for turtle dove across most of the European range (Fisher et al. 2018). Available demographic information is currently largely restricted to studies conducted in the UK and France, and future assessments of hunting sustainability will require reliable measures of productivity and adult survival from across the range and particularly from the large breeding populations in Iberia, France and Italy.

The DIM approach requires the survival rate to be obtained under the most favourable environmental conditions (i.e. it should not be constrained by density-dependence or by the inclusion of anthropogenic sources of additive mortality). For turtle doves this should exclude all types of mortality caused by hunting but should include natural mortality such as that associated with 
migration or predation by native predators. Ricklefs (2000) used the longevity of captive individuals to estimate maximum 'innate' survival in the absence of environmentally limiting factors although in the case of turtle dove this excludes natural mortality associated with migration or predation. In order to obtain more robust DIM model predictions, a temporary moratorium on hunting within the EU might allow the more accurate estimation of optimal population growth and survival rates in the absence of hunting, although ideally hunting would need to cease across the entire flyway, including northern and sub-Saharan Africa (otherwise, the survival estimate used might be lower than optimal rates, with a risk of overestimating the potential maximum harvestable population fraction $\mathrm{P}$ ). We recommend any moratorium would need to last at least five years in order to allow the reliable estimation of population growth and adult survival in the absence of (EU) hunting mortality.

Since the precision of stable age distribution depends on the parameters of the matrix model we used, the precision of all parameters of the matrix should be improved. The precision of productivity parameters is relatively good for the number of fledged chicks per nesting attempt, but could be improved for the number of nesting attempts per season. In any case we recommend annual monitoring of the number of breeding attempts and number of fledged chicks per nesting attempt in order to obtain annual estimates of the proportions of juveniles and adults prior to the hunting season.

Existing national bird monitoring schemes currently provide annual estimates of abundance change for most key breeding populations along the western flyway and should therefore detect any population level response to any changes in hunting mortality. The results of our study suggest that efforts should be made to improve national estimates of population size. Countries often differ in the method they use to estimate population size (see Methods section), with problems of both bias and precision. Further work to improve the precision of population estimates would be particularly useful for countries supporting a high proportion of the flyway population (like Spain, France and Portugal).

An assumption of the demographic invariant method is that there is no age or gender bias in additive mortality. Yet, the question of imbalance of harvest among age classes is an important one: the demographic impact of a given level of harvest depends critically on the distribution of that mortality across groups with differing future reproductive potential (Wade 1998, Niel and Lebreton 2005). In many game bird species, it is common for juveniles to be more heavily harvested than adults (ducks: Guillemain et al. 2010; geese: Madsen 2010; pigeons: Murton 1961, Aubineau 1988; Thrushes: Payevsky and Vysotsky 2003), and this may be enough to make harvest appear as partly compensatory. For future modelling of hunting sustainability, where possible, data on the age and sex composition of the hunted birds should be collected. These data could then be used in more robust statistical approaches, such as matrix population models, to model the effects of harvesting in structured populations (Lebreton 2005).

This DIM approach allows for the detection of potential overharvested of quarry populations but is not intended to inform the process of developing a sustainable harvest modelling framework (Slade et al. 1998, Niel and Lebreton 2005, O'Brien et al. 2017). The DIM method provides an initial assessment of the likely sustainability of current harvest losses, to inform initial management decisions (Taylor et al. 2000), before a long-term sustainable harvest modelling framework can be developed. Although any specific estimate of the maximum harvestable population fraction is subject to various assumptions and uncertainty, we demonstrate that the current levels of turtle dove harvest substantially exceed this maximal harvestable fraction by some considerable margin under the large majority of scenarios we consider. When we adopted the recommended cautious management objective for a globally vulnerable species $(f=0.1)$, current levels of hunting are approximately twice or more the maximum threshold level recommended by the DIM (Table 3). Current hunting levels only approached the recommended DIM thresholds when $\mathrm{f}$ was set to a much less conservative 0.3. Given the perilous conservation status of the European Turtle-dove, the likely under-reporting of legal hunting and the additional sources of additive mortality, the case to 
adopt the more conservative management objective $(f=0.1)$ is strong and we therefore conclude that current levels of hunting along the western European flyway are likely to be unsustainable.

\section{Implications for conservation}

While we acknowledge that attitudes towards uncertainty and management objectives will vary between stakeholder groups, our analysis indicates that a substantial reduction in the size of the current legal western flyway hunt is urgently required. As the western flyway population is continuing to decline (PECMBS 2019), any delay in the implementation of such hunting restrictions will require more severe restrictions at a later date. Such a reduction in legal hunting might be realised either through a complete temporary cessation (i.e. moratorium), or through a substantial restriction on the size of the hunting bag (e.g. through a quota system). A temporary moratorium would be easier to implement, would carry the greatest potential demographic benefit to turtle doves and would potentially allow the measurement of population growth and survival rates in the absence of hunting (a key requirement of the DIM model). However, it would also incur some economic costs on commercial hunting estates and some loss of highly valued cultural services in some countries and regions. Continued hunting may provide incentives for habitat conservation measures carried out by some hunting interest groups that benefit the target species whereas a complete hunting ban might be counterproductive (Madsen et al. 2015). While restrictions on the size of the total hunting bag might be more acceptable to hunting groups, this would be more difficult to implement and enforce, and would probably deliver less demographic benefit for turtle doves. Using quota regulations to limit regional or national hunting bags can be problematic. For example the implementation of daily hunter quota for turtle doves in several regions of Spain since 2007 did not lead to any changes in regional hunting bags (Moreno-Zárate et al. 2018).

Finally, it should be remembered that although the sustainability index (SI) can be used to evaluate whether current levels of harvest are unsustainable, it cannot be used to predict sustainable levels of harvest (Slade et al. 1988, Niel and Lebreton 2005), as it relies upon the maximum, and not the current, population growth rate. More detailed work using matrix models would be necessary to define such sustainable levels of harvest to inform wider management. Considering the different anthropogenic interests, hunting regulations among the range states and the migratory behaviour of the species, a spatially explicit approach may be needed.

Furthermore, even drastic reductions in hunting levels might not bring about any change in the population growth rate if other factors (like the loss or degradation of breeding or wintering habitat) currently outweigh or substitute for the mortality caused by hunting $\left(\mathrm{O}^{\prime}\right.$ Brien et al. 2017). However, our results show that hunting mortality alone is already above the mortality limit defined by the DIM approach and should therefore be reduced.

Along with the search for a sustainable hunting pressure on turtle doves in Western Europe, one should also consider the urgent need to implement effective agri-environmental and agri-forest habitat restoration measures, in particular to maintain or restore the carrying capacity of breeding and foraging habitats. (See for example Walker and Morris 2016, Walker et al. 2018).

\section{Supplementary Material}

To view supplementary material for this article, please visit http://dx.doi.org/10.1017/ So959270919000479.

\section{Acknowledgements}

The authors would like to thank Fred Johnson and Beatriz Arroyo for their useful comments on earlier drafts of this manuscript. 


\section{References}

Arroyo, B., Moreno-Zárate, L., Estrada, A. and Jiménez, J. (2018) Sostenibilidad de la caza de la Tórtola en España. Report for the Ministry of Agriculture, Fisheries and Environment (MAPAMA).

Aubineau, J. (1988) Le pigeon ramier (Columba palumbus) dans le bocage du Centre-Ouest français. Bull. Mensuel O.N.C. 127: 25-29.

Aubry, P., Anstett L., Ferrand, Y., Reitz, F., Ruette, S., Sarasa, M., Arnauduc, J. P. and Migot, P. (2016) Enquête nationale sur les tableaux de chasse à tir. Saison 2013-2014Résultats nationaux. Faune sauvage 310 (supplement): $1-8$.

BirdLife International (2015) The BirdLife checklist of the birds of the world: Version 8. Downloaded from www.birdlife.org.

BirdLife International (2017) Streptopelia turtur (amended version of 2017 assessment). The IUCN Red List of Threatened Species 2017: e.T22690419A119457869. http://dx. doi.org/10.2305/IUCN.UK.2017-3.RLTS. T22690419A119457869.en. Downloaded on o8 January 2019.

Boere, G. C. and Stroud D. A. (2006) The flyway concept: what it is and what it isn't. Pp. 40-47 in G. C. Boere, C. A. Galbraith and D. A. Stroud, eds. Waterbirds around the world. Edinburgh, UK: The Stationery Office.

Boutin, J.M. (2001) Elements for a Turtle-dove (Streptopelia turtur) management plan. Game Wildl. Sci. 18: 87-112.

Boutin J. M. and Lutz, M. (2007) Management plan for Turtle Dove (Streptopelia turtur) 2007-2009. Luxembourg: European Commission.

Brochet A. L., Van den Bossche, W., Jbour, S., Ndang'ang'a, P. K., Jones. V. R., Abdou, W. A. L. I., Al-Hmoud, A. R., Asswad, N. G., Atienza, J. C., Atrash, I. et al. (2016) Preliminary assessment of the scope and scale of illegal killing and taking of birds in the Mediterranean. Bird Conserv. Internatn. 26: 1-28.

Browne, S. J. and Aebischer, N. J. (2004) Temporal changes in the breeding ecology of European Turtle Doves Streptopelia turtur in Britain, and implications for conservation. Ibis 146: 125-137.
Browne, S. J., Aebischer, N. J. and Crick, H. Q. P. (2005) Breeding ecology of Turtle Doves Streptopelia turtur in Britain during the period 1941-2000: an analysis of BTO nest record cards. Bird Study 52: 1-9.

Cramp, S. (1985) The Turtle Dove Streptopelia turtur. Pp. 353-363 in Handbook of the birds of Europe, the Middle East and North Africa. Vol. IV, Terns to Woodpeckers. Oxford: Oxford University Press.

Dillingham, P. W. and Fletcher, D. (2008) Estimating the ability of birds to sustain additional human-caused mortalities using a simple decision rule and allometric relationships. Biol. Conserv. 141: 1783-1792.

Dunn, J. and Morris, A. (2012) Which features of UK farmland are important in retaining territories of the rapidly declining Turtle Dove Streptopelia turtur? Bird Study 59: 394-402.

Dunn, J., Morris, A. and Grice, P. (2017) Postfledging habitat selection in a rapidly declining farmland bird, the European Turtle Dove Streptopelia turtur. Bird Conserv. Internatn. 27: 45-57.

Elmberg, J., Nummi, P., Pöysä, H., Sjöberg, K., Gunnarsson, G., Clausen, P., Guillemain, M., Rodrigues, D. and Väänänen, V-M. (2006) The scientific basis for new and sustainable management of migratory European ducks. Wildlife Biol. 12: 121-127. Eraud, C., Boutin J. M., Riviere, M., Brun, J., Barbraud, C. and Lormée, H. (2009) Survival of Turtle Doves Streptopelia turtur in relation to western Africa environmental conditions. Ibis 151: 186-190.

Escandell, R. (2011) The Turtle Dove, in "Spring migration in the western Mediterranean and NW Africa: the results of 16 years of the Piccole Isole project", Monografias del Museu de Ciencias Naturals 6: $31-37$.

European Union (2009) Directive 2009/147/EC of 30 November 2009 on the conservation of wild birds. http://eur-lex.europa.eu/legalcontent/EN/TXT/?uri=CELEX:32014RI320

Fisher, I., Ashpole, J., Scallan, D., Proud, T. and Carboneras, C. (compilers) (2018) International Single Species Action Plan for the conservation of the European Turtle-dove 
Streptopelia turtur (2018 to 2028). Luxembourg: European Commission.

Guillemain, M., Bertout, J. M., Christensen, T. K., Pöysä, H., Väänänen, V. M., Triplet, P., Schricke, V. and Fox, A. D. (2010) How many juvenile teal Anas crecca reach the wintering grounds? Flyway-scale survival rate inferred from wing age-ratios. J. Ornithol. 151: 51-60.

Jarry, G. (1980) Dynamique d'une population d'Hirondelles rustiques, Hirundo rustica L., dans l'est de la région parisienne. L'Oiseau et R.F.O. 50: $277-294$.

Jarry, G. (1995) Tourterelle des Bois Streptopelia turtur. Pp. $380-383$ in D. YeatmanBerthelot and G. Jarry, eds. Nouvel atlas des oiseaux nicheurs de France. Paris: SOF.

Johnson, F. A., Walters, M. A. and Boomer, G. S. (2012) Allowable levels of take for the trade in Nearctic songbirds. Ecol. Appl. 22: 1114-1130.

Lebreton, J.-D. (2005) Dynamical and statistical models for exploited populations. Aust. N. Z. J. Stat. 47: 49-63.

Lebreton, J. D., Burnham, K. P., Clobert, J. and Anderson, D. R. (1992) Modeling survival and testing biological hypotheses using marked animals - A unified approach with case studies. Ecol. Monogr. 62: 67-118.

Madsen, J. (2010) Age bias in the bag of pinkfooted geese Anser brachyrhynchus: influence of flocking behaviour on vulnerability. Eur. J. Wildl. Res. 56: 577-582.

Madsen, J., Guillemain, M., Nagy, S., Defos du Rau, P., Mondain-Monval, J. Y., Griffin, C., Williams, J. H., Bunnefeld, N., Czajkowski, A., Hearn, R., Grauer, A., Alhainen, M. and Middleton, A. (2015) Towards sustainable management of huntable migratory waterbirds in Europe: a report by the waterbird harvest specialist groups of Wetlands International. Wageningen, The Netherlands: Wetlands International.

Marx, M., Korner-Nievergelt, F. and Quillfeldt, P. (2016) Analysis of ring recoveries of European Turtle Doves Streptopelia turtur - flyways, migration timing and origin areas of hunted birds. Acta Orn. 51: 55-70.

Moreno-Zàrate, L., Peach, W. J. and Arroyo, B. (2018) Limitations of current policy in Spanish hunting for the conservation of European-Turtle dove. Poster, In Pathways
Europe 2018 Conference-16-19 September 2018 - Goslar, Germany.

Murton, R. K. (1961) Some survival estimates for the Woodpigeon. Bird Study 8: 165-173.

Niel, C. and Lebreton, J. D. (2005) Using demographic invariants to detect overharvested bird populations from incomplete data. Conserv. Biol. 19: 826-835.

O'Brien, S. H., Cook, A. S. C. P. and Robinson, R. A. (2017) Implicit assumptions underlying simple harvest models of marine bird populations can mislead environmental management decisions. J. Environ. Manage. 201: 163-171.

Payevsky, V.A. and Vysotsky, V. G. (2003) Migratory Song Thrushes Turdus philomelos hunted in Europe: survival rates and other demographic parameters. Avian Sci. 3: 13-20.

PECBMS (2019) Species trends. Pan-European Common Bird Monitoring Scheme. Available from https://pecbms.info/trends-andindicators/species-trends/

Ricklefs, R. E. (2000) Intrinsic aging-related mortality in birds. J. Avian Biol. 31: 103-111.

Robinson, J. G., and Redford, K. H. (1991) Sustainable harvest of Neotropical forest animals. Pp. 415-429 in J. G. Robinson and K. H. Redford, eds. Neotropical wildlife use and conservation. Chicago: University of Chicago Press.

Runge, M. C., Sauer, J. R., Avery, M. L., Blackwell, B. F. and Koneff, M. D. (2009) Assessing allowable take of migratory birds. J. Wildl. Manage. 73: 556-565.

Schulz, J. H., Padding, P. I. and Millspaugh, J. J. (2006) Will mourning dove crippling rates increase with nontoxic-shot regulations? Wildl. Soc. Bill. 34: 861-865.

Seber, G. A. F. (1982) The estimation of animal abundance. London: Edward Arnold.

SEO/BirdLife (2012) Análisis preliminar del banco de datos de anillamiento de aves del Ministerio de Agricultura, Alimentación y Medio Ambiente, para la realización de un atlas de migración de aves de España. Madrid: SEO/BirdLife-Fundación Biodiversidad.

Siriwardena, G. M., Baillie, S. R., Crick, H. Q. P., Wilson, J. D. and Gates, S. (200o) The demography of lowland farmland birds. Pp. 117-133 in Ecology and conservation of 
lowland farmland birds. Proceedings of the 1999 BOU Spring Conference. Tring: BOU.

Slade, N. A., Gomulkiewicz, R. and Alexander, H. M. (1998) Alternatives to Robinson and Redford's method of assessing overharvest from incomplete demographic data. Conserv. Biol. 12: 148-155.

Sorrenti, M. and Tramontana, D. (2016) Estimate of turtle-dove Streptopelia turtur harvest in Italy. Federazione Italiana della Caccia - Ufficio Avifauna Migratoria.

Spina, F. and Volponi, S. (2008) La tortora selvatica (Streptopelia turtur) In Atlante della Migrazione degli Uccelli in Italia. 1. nonPasseriformi. Roma: Ministero dell'Ambiente e della Tutela del Territorio e del Mare, Istituto Superiore per la Protezione e la Ricerca Ambientale (ISPRA). Tipografia CSR-Roma. Taylor, B. L., Wade, P. R., DeMaster, D. P. and Barlow, J. (2000) Incorporating uncertainty into management models for marine mammals. Conser. Biol. 14: 1243-1252.
Wade, P. R. (1998) Calculating limits to the allowable human caused mortality of cetaceans and pinnipeds. Mar. Mammal Sci. 14: 1-37.

Walker, L. K. and Morris, A. J. (2016) Evaluating Turtle-dove HLS Package. Report to Natural England Work Package Number ECM6924. (https://www.operationturtledove.org/2017/ 12/08/working-together-turtle-doves-launchturtle-dove-friendly-zone/)

Walker, L. K ., Morris, A. J., Cristinacce, A., Dadam, D., Grice, P. V. and Peach, W. J. (2018) Effects of higher-tier agri-environment scheme on the abundance of priority farmland birds. Anim. Conserv. 21: 183-192.

Williams, B. K., Conroy, M. J. and Nichols, J. D. (2002) Analysis and management of animal populations. San Diego: Academic Press.

Zwarts, L., Bijlsma, R., Van der Kamp, B. and Wimenga, E. (2009) Living on the edge: Wetlands and birds in a changing Sahel. Zeist, The Netherlands: KNNV Publishing. 